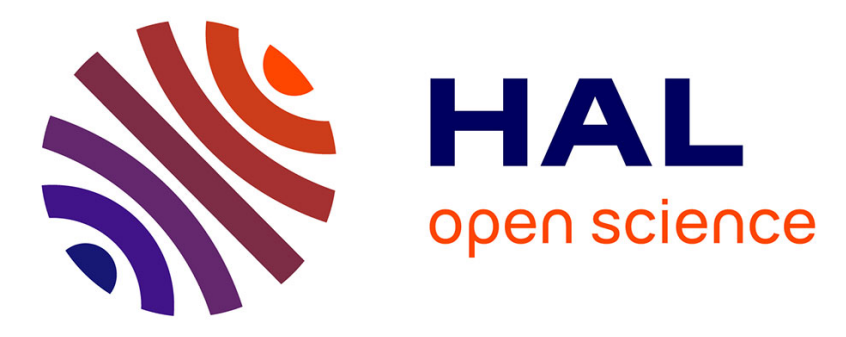

\title{
Semiotic Narrativization Processes
}

Nicolas C.M. Marty

\section{To cite this version:}

Nicolas C.M. Marty. Semiotic Narrativization Processes. Leuven University Press. Music, analysis, experience. New perspectives on musical semiotics, , pp.97-114, 2015, 9789462700444 . hal01318859

\section{HAL Id: hal-01318859 \\ https://hal.science/hal-01318859}

Submitted on 20 May 2016

HAL is a multi-disciplinary open access archive for the deposit and dissemination of scientific research documents, whether they are published or not. The documents may come from teaching and research institutions in France or abroad, or from public or private research centers.
L'archive ouverte pluridisciplinaire HAL, est destinée au dépôt et à la diffusion de documents scientifiques de niveau recherche, publiés ou non, émanant des établissements d'enseignement et de recherche français ou étrangers, des laboratoires publics ou privés. 


\section{Semiotic Narrativization Processes}

Nicolas Marty

Université Paris-Sorbonne

\section{Introduction}

Fludernik (2002) talked about narrativization as the imposition of narrativity by a receiver on an object. Roughly, this means that narrativity is not a stable characteristic of an object, but rests on the receiver's experience of the object.

This point of view can prove fruitful when applied to the study of acousmatic music listening. In fact, it allows for the distinction between a narrative as a recountal of events and narrativity as the quality of anything that might be made into a narrative. Fludernik (2002) emphasized that for something to be made into a narrative, there needs to be experientiality and/or consciousness at some level. Therefore narrativization, to be effective, implies the centration of experientiality by the receiver.

In literature, experientiality is often centered on the (pre-defined) character(s) and/or narrator(s). In acousmatic music, other possibilities are just as likely to be used by the listener. We can therefore distinguish between three kinds of narrativization, relying on three points of focalization:

- Egocentered focalization (considering the listener's own experience) induces embodied narrativization;

- heterocentered focalization (considering the experience of another being) induces ecological narrativization - "ecological" reffering to a sense of analogy to natural world relations ;

- and exterocentered focalization precedes semiotic narrativization. In instrumental music, the most significant and relevant processes are those of semiotic narrativization, reliant on propositional/conceptual cognitive representations (since instrumental music often does not offer ecological, spatial, pictorial perspectives as does acousmatic music). These will be the topic of this paper. 


\section{Memory, abstraction, semiotization}

The following developments are founded on two distinctions made in the field of psychology. As we will see in what follows, it is helpful to distinguish between semiotic narrativization processes according to their degree of abstraction, to the kind of long-term memory they imply, and to their "verbalizability".

Psychologists distinguished between several kinds of long term memory, related to the opposition between encyclopaedic and contextual encoding - semantic and episodic memories - as well as between automatic or voluntary recuperation implicit and explicit memories (Meunier, 2009, p. 39, 41 ${ }^{\mathrm{i}}$ ).

This is to be taken into consideration since no cognition can rely on sole immediate experience - in other words, cognition is always the product of both immediate experience and its relation to the context, the listener (or any cognizing entity) and his/her past experience. Here we will not be able to study what listeners make out of their listening experience, but rather through which processes (besides those ecological processes described in Marty, 2012a).

Piaget described several types of processes of abstraction (Bideau, 2007, p. 53-54). Empirical abstraction is thus constituted of data drawn from perception (I play with rocks, I count them: there are five); reflecting abstraction draws data by linking together several empirical abstractions (I organize the rocks in a circle, I count them; I make a line, I count them; I put them sparsely, I count them: in all cases, there are five); and reflexive abstraction consists in drawing data from the relation between several reflecting abstractions, allowing the detachment from perception (I play with rocks, candies, dolls: when I count them, whatever the form, the proportion, there are five: "five" may then be a value that can exist besides the empirical existence of objects).

We thus obtain three kinds of processes:

- PROPRIOCEPTIVE SEMIOTIZATION PROCESSES, unverbalizable because emanating from implicit memory, reliant on a process of empirical abstraction: I perceive a sonic stimulus, my body reacts in a certain way and I observe this reaction. One could consider those to be the "less semiotic" semiotization processes, because they involve only the listener's body and conscience. But once the listener starts to observe his/her own experience, rather than live it passively, there is an abstracting process at work, that of "meta-cognition". 
- ASSOCIATIVE SEMIOTIZATION PROCESSES, verbalizable without much loss, linked mainly to episodic (implicit or explicit) memory, reliant on a process of reflecting abstraction: I observed my body's reactions and/or constructed an imaginary world/diegesis (through ecological narrativization - which is partly an empirical abstraction, since it cognizes sound into its pictorial form): what do they remind me of?

- ANALYTICAL SEMIOTIZATION PROCESSES, based on (immediate or preceding) verbalization, reliant on semantic (explicit) memory and processes of reflexive abstraction: I realize that this particular sequence of sounds always has the same effect on me and/or reminds me of the same things: maybe the sequence has a value in itself: a "perfect cadence"?

Let us study each of those kinds of semiotic narrativization. For now it is quite important to understand that "semiotic narrativization" (or "semiotization") will refer along this paper to any kind of abstracting cognitive process. Furthermore semiotization (and narrativization) being a mixed, multi-dimensional process, we could wonder as to what constitutes the relations between the three kinds drafted here. Between proprioceptive and associative semiotizations, one could hope to find "affect", whereas between associative and analytical semiotizations, there would stand "storification" (the actual making of a narrative - however basic and protoverbal). In between proprioceptive and analytical semiotization, one could hope to find (auto)psychoanalytic processes as well as plain analytic process enlightened by embodied appreciation. All of these will not be developed further here, mainly because they are far too complex.

\section{Towards feelings (proprioceptive semiotization)}

We will briefly review the spatial, temporal, and morphological semiotics in order to offer several possibilities for the proprioceptive analysis of a work. Proprioceptive semiotization processes being the result of an empirical abstraction of temporal, embodied experience, one could hypothesize that they are the semiotization of a more "primary" kind of narrativization - kinesthetic proto-narrativization ${ }^{\mathrm{ii}}$ - which is prior to conscious perception and results from empathy (for instance with animal utterances) and dynamic vectors (see below) that are semiotized only as long as the listener places him/herself as an observer of his/her own kinesthetic experience. 


\subsection{Music, embodiment and the gestural/spatial semiotics}

Other than the attribution of an intention to sound - mentioned in Khosravi (2012) with the notion of "autonomous spectromorphological entities", as well as in Marty (2012a) with the "anthropomorphization" of sounds - there seems to be an embodied aspect to the movement of sound, whether spatial, melodic or spectral. Imberty explains the similitude between the act of singing and the hearing of singing, where one finds in oneself, "at least allusively, a kinesthetic representation of those gestures and movements that command the action of singing and the melodic gestures it produces" (2010a, p. 14).

Moreover, the gestural aspect inherent to the sound's morphology (which includes melodic, spatial, harmonic, spectral and temporal characteristics) is emphasized by Faure (2000, p. 163), who reminds us of young children's gestural experimentations with sounds.

The question is extremely wide, but seems to rest on the interpretation of stimuli according to embodied criterion: how could I produce this sound? How could I produce this gesture? What would this production do to my body? What does it do to my body? All of those questions (and more) would be asked and resolved implicitly at the very moment when the sound is perceived.

\subsection{The proto-narrative envelope and time semiotics}

Imberty focused his research on time perception and its relation to music and musicality. The first thing is that time has a subjective layer which can be developed in the idea of a "thickness in present". One could then talk about the "past in present", "present in present" and "future in present" (Imberty, 2005, p. 233).

From this grows the idea of a "proto-narrative envelope", coined by Daniel Stern (1995) as an "intuitive dramatic tension thread" (Imberty, 2005, p. 234) that leads to the narrative perception of self through the association with oneself of the phenomena and experiences to which one is confronted. This proto-narrative envelope develops in early childhood with the repetition and "re-presentation" of a stimulus that provokes the "after-effect" - i.e. the encoding of a time-oriented phenomenon as a whole in memory (p. 235). 
This leads to the idea of the dynamic vector as a musical event "which carry temporal meanings of orientation, progression, diminution or growth, repetition or retrospection" (Imberty, 2010b, p. 2).

An experiment with Debussy's La Puerta del Vino allowed Imberty to demonstrate the existence of such vectors in music listening: in the piece's coda, with the sudden change to high register, verbal description of listeners are all relative to a stopping of time, a serenity. It is this change that Imberty qualifies of dynamic vector, because it will change the perception and expectations of the listener, as well as his/her cognitive representations, which will lead to a semiotization of time.

\subsection{Six models for a hermeneutical analysis}

Baboni (2008) formulated a theory that maintains the existence of a "hermeneutic circle" which rests on need, desire and consideration and is valuable in analyzing the experience of a work of art, on an embodied model.

To him, need is born from alteration of a state of equilibrium which becomes a state of tension. The logical consequence for a need is to search for its satisfaction. Desire is the relation of several needs of which combined satisfactions may provoke pleasure. Consideration is the categorization process that allows for the efficient interpretation of a phenomenon through its relation to "marks groups".

From the relation between need, desire and consideration, are drawn six models for a hermeneutical analysis, each of which originates from a bodily experience of early childhood and treats an aspect of the system of the contemplated work of art (Baboni in Marty, 2012b, p. 211-213). The first two models (attractivity and cyclicity) study stasis, dynamism and their interactions in the musical system, as observed through an embodied perspective - this is linked, for instance, to the polar nature of the tonic in tonal music. The third model (corruptibility) answers to the possibility for the dissolution or disappearance of the system - can the system be contradicted in a way that does not lead to a new understanding of it, but rather to the necessity for a new system? -, whereas the fourth and fifth models (constructivity and destructivity) treat the development and growth, or reduction and shrinking, of the system's rules towards a new understanding of the system. The sixth model (excitability) answers the question of satisfaction in itself, for oneself, which one seeks in contemplation. Baboni 
is more elusive about this model and seems to leave it at a more abstract stage that the five others.

We are thus in an embodied system. Music, rather than being only "narrating itself", may then be understood as the appraisal of a system's evolution resting on its embodied understanding: "the hermeneutic circle is the search for a [embodied] semantic meaning (verbalizable or not) to the work of art that is contemplated, but also to the system to which the work seems to belong" (Baboni, 2008, p. 65). Considering briefly an extension of this process towards analytical semiotization, this contemplation of the work's system may be correlated with the making of the (out-oftime) cognitive representation of a work by a listener who evaluates the system's possible states and transitions through a more or less explicitly stochastic view - what Chouvel described using the physics/mathematics concepts of "phase space" and "Markov chains" (2006, p.139, 145).

\section{Towards meaning (associative semiotization)}

We saw with proprioceptive semiotization the influence of implicit memory on the apprehension of music. Let us turn to the influence of episodic memory, related to imagination and association of ideas, on semiotic (reflecting - that is, founded on the comparison of several empirical informations) abstraction.

\subsection{Verbal induction}

As Francès already noted, music's representative effects are polarized by the verbal elements given before or during musical audition (2002, p. 279).

This effect is very well-known and takes an important part in the success of programmatic music with children and "naïve" listeners, among others, by allowing them to listen to music through a formal schema that they can easily conceive: instead of being perceived as an abstract, emotional form, musical form is related to images and stories - without necessarily becoming a story itself.

The BBC tried to use verbal induction for the 1978 diffusion of Andrew Sachs' The Revenge, first (and mainly last) radio drama without words. The title of the piece was announced two times, at the beginning and end of diffusion, evidently to make up for the complete absence of indicators of motivation, aim or goal in the work itself, which pictures a man who is probably escaping from a prison, goes into town and kills 
somebody or gets killed himself at the end, without a single instance of verbal language - this participates in the non-human aspect of the work.

It seems important to emphasize that a narrativization resulting from a title or a program is not necessarily verbalized (either as a narrative, as characters' names or anything else) - it can be manifest only at a pictorial level. But when it actually includes (silent or overt) verbalization, it could be related to symbolism, of which I will talk later.

\subsection{Cultural synaesthesia}

In 1980 Lakoff and Johnson wrote Metaphors we live by (2003), which would become the basis for their subsequent research on the integration of philosophy, perception and cognition in an anthropomorphic, embodied frame. To them, "our conceptual system plays a central role in defining our everyday realities" (p. 3) rather than just being an arbitrary linguistic system.

Those metaphors will be the basis for what can be called "cultural synaesthesia" that is, a kind of metaphorical correspondence between senses. This way, one can associate (more or less conventionally) colors, smells, textures to sounds, this being different from authentic synaesthesia which seems to be the product of a neurological, less cultural phenomenon - though some have hypothesized that both kinds of synaesthesia are closely related and always cognitively cultural (see Rosenthal, 2011). We will focus here on the most common metaphor in music: the association of pitch height with vertical height - this is what Lakoff and Johnson call an "orientational metaphor". This kind of metaphor does not seem to be arbitrarily decided, but rather rests on human embodied experience: if HIGH is HAPPY, and LOW is SAD, it may be because (at least in our culture) being happy tends to make one raise his/her head, whereas being sad tends to do the contrary, making one lower his/her head (Lakoff and Johnson, p. 18).

Baboni effectively explains our metaphor with an interesting model, differing from the most common "low pitches come from the thoracic cage, high pitches are closer to the head": pitch height being correlated to the bodily tension that produces it (tenser produces higher pitches), this same tension allows us to stand up from the ground, to 
resist to gravity. The more one relaxes, the lower one gets (Baboni in Marty, 2012b, p. 211-213).

A kind of gravity applied to music (Roy, 2001, p. 458) would thus explain the fact that melodies all around the world tend to descend, even if they often finish at the same pitch they began because ascending gestures are wider than descending ones (Meeùs in Marty, 2012b, p. 219-221).

But it may be forgetting the cultural aspect of the orientational metaphor, underlined by Lakoff and Johnson when they say that all cultures do not give the same priority as us to the high/low orientation (Lakoff and Johnson, p. 24), and that inside a given culture there lie metaphors that do not function together but still apply to the same concepts - emphasizing different aspects of it (p. 220-221). The metaphor is cultural and built on embodied origins, but also on a social and musical convention that is perfectly established today in Occident: the spatial-vertical representation (see Duchez, 1979).

Still, many works tend to prove that no matter the culture, acousmatic cognitive images are built in a spatial fashion, higher frequencies corresponding to higher locations (relative to the body of the listener), this being explained by several psychoacoustical factors which are not the topic of this paper (see Khosravi, 2012; Kendall and Ardilla, 2008). Furthermore there are many other "cross-domain mappings" relative to pitch or other dimensions, which do not necessarily imply the verticality metaphor. Furthermore, this metaphor could easily be used to make assumptions about metaphorical maps (e.g. UP is GOOD / HIGH PITCH is SPATIALLY HIGH $\rightarrow$ HIGH PITCH is GOOD) that may have no reality in a listener's apprehension of sound or music (see Eitan and Timmers, 2010).

\subsection{Unconscious association}

Another kind of associative semiotization imposes associative preconceptions on a new musical element in an unconscious fashion. Any resemblance with a known phenomenon, with no need for verbalization, will aid (or even induce) the same listening strategies used to apprehend the phenomenon the first time. Along with this, images and evocations induced by the first phenomenon will be activated in working memory and will thus be available for easier recuperation by the listener. 
Nattiez gives an example of this type of process in the case of the use of pre-existing music in movies: according to him, anyone who listens to Strauss' Also sprach Zarathustra and who saw 2001 Space Odyssey cannot help but make the association with intersidereal space, for instance (2003, p. 275).

Thus are installed what we can call "musical clichés", through the automation of a symbolism that limits the apprehension of a musical work or sound, such as the "eerie" sound of a flute, or the vampires who come with a cello playing on modal scales with way too much reverberation.

But let's not forget the limit of this trail of thought: every automated thing is not necessarily cliché. It can also be an archetype, when the symbolic relation is founded on 'natural' (Human) properties of the symbolic entities. The sound of water may evoke life without being cliché, because the archetype rests on the necessity of water to survive, a thing common to all humans. However, using water deliberately to evoke life may be considered cliché. Through more complex associations, a more profound symbolic may be instated.

\section{Towards concept (analytical semiotization)}

The third kind of semiotic narrativization is necessarily verbalized (though verbalization may be prior to listening, as in the case of guided categorization) because its existence relies fundamentally on its verbalization and/or conceptualization. The consideration of number/letter symbols (i.e. B-A-C-H) is relevant here: even if it is not primordial in the understanding of music, the symbol is the origin of a compositional - poietic - development (Boulez, 2005, p. 434-435). The sociological and political analysis of musical works is another kind of conceptualism, which hypothesizes a link between the creation and its historical context. We will talk here about symbolism, conceptualism and "musical" analysis. "Musicological" listening - identifying tonalities, chords, modulations, etc. - may also enter this frame because, as Schaeffer's typomorphology, it is a (somewhat arbitrary?) categorization system that imposes the listening of some properties and characteristics as being more relevant than others - which may sometimes lead to a completely unsatisfactory listening experience. 


\subsection{Conscious association (symbolism)}

Beyond unconscious associations appear symbolisms, verbalized and reflexive, which allow to overcome established clichés in order to apply new meanings to music. The two kinds of associations are closely linked by the possibility for the automation of the symbolism as cliché. Thus the dotted rhythm of a march, before becoming a largely understood cliché (even if it is founded on physical parameters), was a symbolism designating the march itself.

The most explicit instance of reflected symbolism is that of baroque music, particularly in Germany, which was conceptualized in a large number of music dictionaries - a high-pitched note would thus represent height or the sky, for instance, while a chromatic semitone would express suffering and pain, and so on. "With the help of those figures, the text is put into music and interpreted/performed" (Ulrich, 1990, p. 305).

The "implicit" listener (see Kaltenecker, 2010) thus knows all the correspondences that allow the appreciation of music in its whole and arrives at the concert having studied the theories of ethos, topö̈ and other rhetorical figures for music. Listening to music, s/he interprets each melodical, rhythmical figure as being the representation of something that exists in the real world or as having a rhetorical, discursive, or even narrative function.

Sometimes, as in Wagner's operas, Prokofiev's Peter and the Wolf, or even TV series Lost or Fringe, the symbolic becomes evident through the simultaneous presentation (verbally or not) of an action, a plot, a narrative and musical motives, themes, which acquire at this point their symbolic or associative value - according to the listener's reception strategies. This question is much more complex than this, of course.

\subsection{Conceptualism}

We will thus turn to the works in which the "con-text" is just as important as, or even more important than, the "text". We might call such works "conceptual", if this adjective hadn't taken on a negative and contemptuous connotation for many people (at least in France).

Cage's 4'33" is such a work, of which the musical/sonic content is not the end in itself, or at least not as much as the concept of music and the presence of silence in a world becoming afraid of it as muzak $k^{\mathrm{iii}}$ fills the last places where one could hear 
his/her own footsteps. In fact, Cage originally envisioned selling a four minutes silent piece to Muzak Holdings Co. under the name Silent Prayer, to give silence to be heard (Kim-Cohen, 2009, p. 16-17).

In the case of "sound art" or "sound sculpture", we find Vitiello's 1999 recordings of the World Trade Center, to have acquired a very strong conceptual value after 9/11, becoming the last words of the towers, of the "pre-9/11" world (Kim-Cohen, p. 130131).

The artist's work is then conceptual in that it demands to be known and understood to allow for the "correct" interpretation (if there is such a thing) of the work. It needs to be understood that even if each musical or sound work has a conceptual aspect, be it only in its style, this aspect is not necessarily discursive and seems to be often treated at the level of unconscious association. In our examples, the text is important, but its con-text is even more so, giving a musical/sound vision, but claiming a political/historical perspective.

In Wishart's work, “concrete metaphors” are excellent examples of concepts asking for verbalization to be understood. In Journey into Space, Wishart tries to imply a metaphor by inducing a change of focus of attention towards a sound's human and mechanical nature (1996, p. 166). We could compare this with the famous rabbit/duck image. Although we may perceive the two forms, we generally don't make any conceptualization that would lead us to learn or even infer something about rabbits and ducks.

Still, Wishart's Red Bird (1978) makes a bit of a point about this, using mainly animal, human and machine sounds, which may put the listener in a mind to relate those elements and put their relation into question (maybe even more so in the 1980s). But - as Wishart says himself - the point of the piece is elsewhere, in the morphings and interpolations that he used and continues to use today.

\subsection{Musical analysis, visual and formal semiotics}

We will close with a last kind of analytical semiotization: musical analysis. The question is very large and led to many critical claims - not the least of which being addressed to serial, algorithmic music, retrogradable rhythms founded on mathematical relations having apparently no perceptive relevance. ${ }^{\text {iv }}$ Questions about macrostructure and its perception were asked more than once. 
Meeùs sees three problems in musical analysis, all of which are born from the out-oftime segmentation of the work: could we really hierarchise levels of observation, transfer local procedures to a more global level or even try and talk about time with such a conception? (1994, p. 22-23)

The notation itself induces the possibility of a segmentation of the work and allows studying it outside of its time of performance (outside of its musicality?). Sheperd says that it is because of notation that the "ideals" of listening and composition are realized on an extremely wide time, nearly observed out of time (1980, p. 111). Wishart raises the question of the normalization of the listening by the listener, due to the limitation of notation to very general parameters with very few variables, which only allow for "an attempted realization of a conglomerate of Ideal (i.e. non-existent) sound-events approximated by proper attention to the notes, the counting, and the 'correct' instrumental timbre production" (1980, p. 144-145).

Even if this way of seeing things is really dramatic and not necessarily applicable to all written music nor to all listening situations, it is nevertheless relevant: the repetition of the octave (even if founded on physical/physiological parameters), just like the domination of pitch, are conventions too - let us simply consider our contemporary serious music, in which timbre is often much more important than pitch! Moreover, even melodic orientations are influenced by notation: flats go down, sharps go up. What if we had a twelve-note system without alterations?

Regarding narrativization, we can conclude that knowledge of the score (or of its form) may induce in the listener the basis for a semiotization strategy that will correspond to the aspects put forward by the notation used. Form may also be created, parts related, via the score - but all this may influence the listening strategy and its consideration (extended formal listening being glorified while immediate, experienced listening is relegated to "naïve" listeners).

\section{Synthesis}

The model is summarized below (Figure 1) in a simplified version. Although arrows, spatial positioning and boxes may give an impression of modular, hierarchized cognitive model, I would like to stress that not one listening mode is "better" than another. The main idea of such a model is to allow for the study of listening rather than the study of music pieces. In the long term, I hope to be able to develop an 
approach for the didactics of acousmatic listening so that - ideally - people may actively find a satisfactory and rich experience in listening to any music or sound phenomenon.

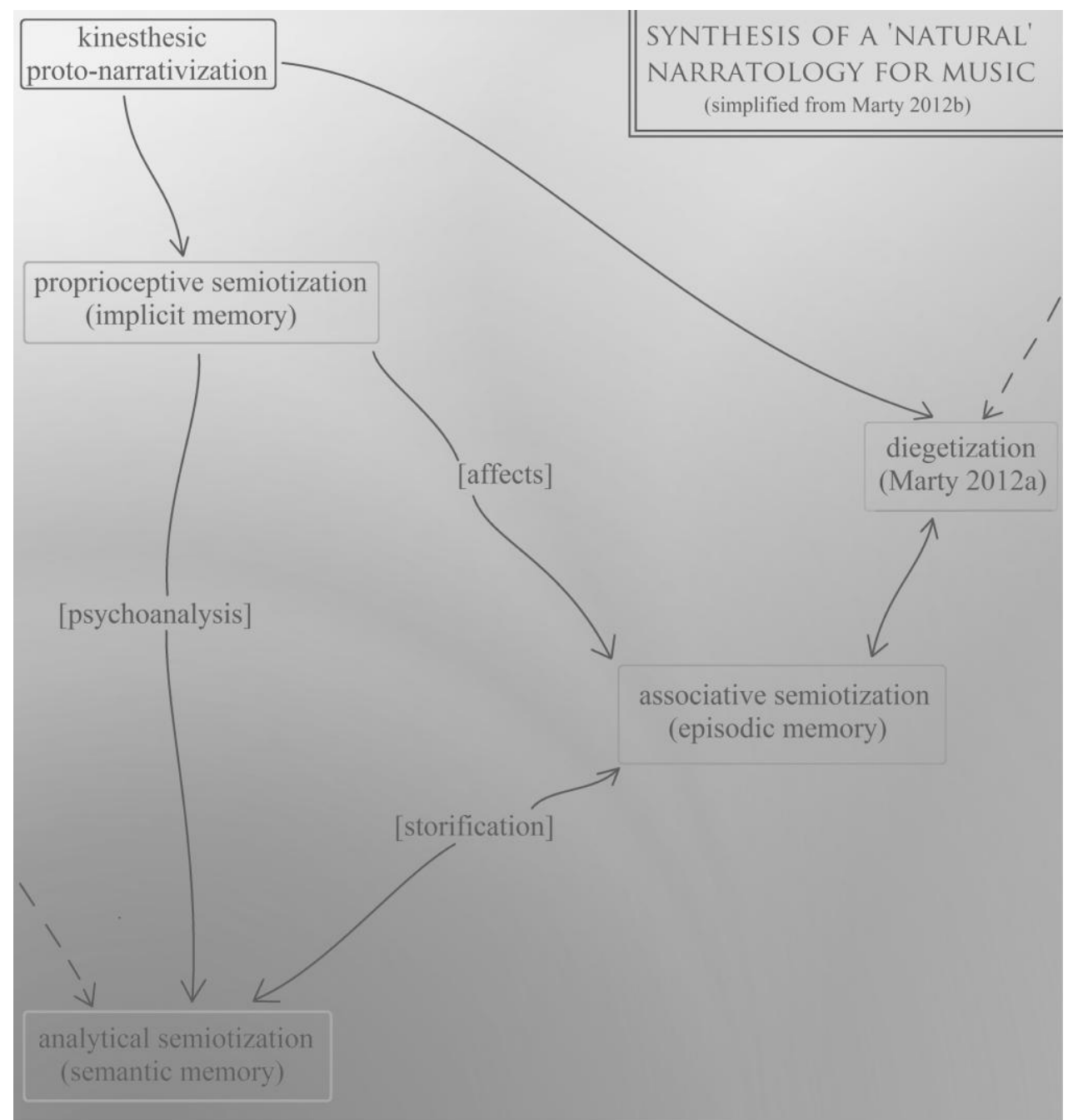

EGOCENTERED FOCALIZATION EMBODIED NARRATIVIZATION
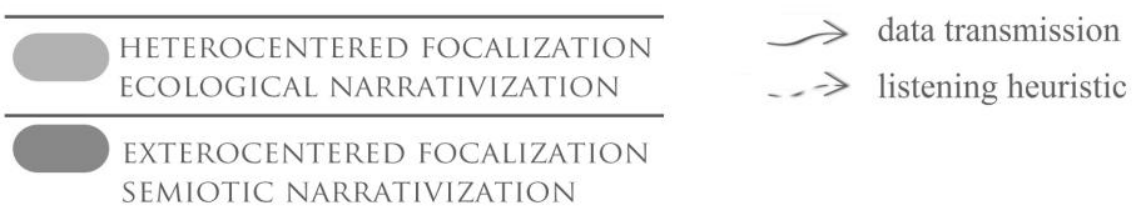

Figure 1

A bit of food for thought: what happens... when we study a score as if studying music? ...when we listen to music as if reading a score? ... when we segment a piece into themes and motives as if they had an intrinsic existence? ... when we listen to acousmatic music searching for variables relevant to tonal music? 
What would happen if we considered music as if it were a mode of reception rather than a means of communication? ...

\section{References}

Baboni-Schilingi, J. and Vallos, F. (2008). Six modèles d'analyse herméneutique. Paris: MIX.

Bideau, J. (2007). La théorie piagétienne. In S. Ionescu and A. Blanchet (Eds.), Psychologie du développement et psychologie différentielle (pp. 37-57). Paris: PUF. Boulez, P. (2005). Regards sur autrui - Points de repère II. Paris: Christian Bourgeois Éditeur.

Chouvel, J.M. (2006). Analyse musicale - Sémiologie et cognition des formes temporelles. Paris: l'Harmattan.

Coker, W. (1972). Music and Meaning: a Theoretical Introduction to Musical Aesthetics. New York: Collier-Macmillan.

Duchez, M.E. (1979). La représentation spatio-verticale du caractère musical graveaigu et l'élaboration de la notion de hauteur de son dans la conscience musicale occidentale. Acta Musicologica, Vol. 51/1, pp. 54-73.

Eitan, Z. and Timmers, R. (2010). Beethoven's last piano sonata and those who follow crocodiles: Cross-domain mappings of auditory pitch in a musical context. Cognition, Vol. 114, pp. 405-422.

Faure, A. (2000). Des sons aux mots : comment parle-t-on du timbre musical ? Ph.D. thesis in cognitive sciences, dir. S. McAdams. Paris: École des Hautes Études en Sciences Sociales. Retrieved May 1, 2013, from http://tel.archivesouvertes.fr/docs/00/14/05/21/PDF/These_Anne_Faure.pdf Fludernik, M. (2002). Towards a 'Natural' Narratology. London / New-York: Routledge.

Francès, R. (2002). La perception de la musique. Paris: J.Vrin. Imberty, M. (2005) La musique creuse le temps - De Wagner à Boulez : Musique, psychologie, psychanalyse. Paris: 1'Harmattan.

_ (2010a). Au-delà de la psychologie cognitive de la musique. In F. Madurell and P. Lalitte (Eds.), Musique et sciences cognitives ("Conférences et séminaires", n46, pp. 9-31). Université Paris-Sorbonne: OMF. 
— (2010b). Souvenirs et réflexions autour de La perception de la musique.

In L. Guirard (Ed.), 50 ans de psychologie de la musique - L'école de Robert Francès (pp. 34-57). Montauban: Alexitere.

Kaltenecker, M. (2010). L'oreille divisée : les discours sur l'écoute musicale aux XVIIIe et XIXe siècles. Paris: MF.

Kendall, G. and Ardilla, M. (2008). The Artistic Play of Spatial Organization: Spatial Attributes, Scene Analysis and Auditory Spatial Schemata. In R. Kronland-Martinet, S. Ystad and Kristoffer Jensen (Eds.), Computer Music Modeling and Retrieval: Sense of Sounds (LNCS series, "Springer Verlag”, Vol. 4969, pp. 125-138).

Khosravi, P. (2012). Spectral Spatiality and the Acousmatic Listening Experience:

The Birth of Autonomous Spectromorphological Entities. Ph.D. thesis in electroacoustic composition, dir. D. Smalley. London City University.

Kim-Cohen, S. (2009). In the Blink of an Ear: Towards a Non-Cochlear Sonic Art.

Continuum International Publishing Group.

Lakoff, G. and Johnson, M. (2003). Metaphors we live by. Chicago University Press.

Marty, N. (2012a). Sonic Identification and Listening Strategies - Towards a

'Natural' Narratology for Electroacoustic Musics. EMS-12 Conference Proceedings.

Stockholm. Retrieved May 1, 2013, from http://www.ems-

network.org/IMG/pdf_EMS12_marty.pdf

— (2012b). Identification sonore, stratégies d'écoute et narrativités. M.Mus. thesis in music and musicology, dir. F. Madurell. Université Paris-Sorbonne.

— (2013). Furthering the Bases of a 'Natural' Narratology for Music. Lecture at the ENN2013 Conference. Paris.

Meeùs, N. (1994). De la forme musicale et de sa segmentation. Musurgia, Vol. 1, nº1, pp. 7-23.

Meunier, J.M. (2009). Mémoires, représentations et traitements. Paris: Dunod.

Michels, U. (1990). Guide illustré de la musique (Volume 2). Paris: Fayard.

MIM (2009). UST - Modifications. In MIM website. Retrieved February 9, 2012, from www.labo-mim.org/site/share/ust/download2.php\%3Ffile\%3DFiches_

UST_Modifs.pdf

Nattiez, J.J. (2003). La signification comme paramètre musical. In J.J. Nattiez (Ed.), Musiques - Une encyclopédie pour le XXIe siècle - tome 2 (pp. 256-287). Paris: Actes Sud. 
Rosenthal, V. (Ed.). (2011). Synesthésie et Intermodalité / Synesthesia and Intermodality (Intellectica, $\left.\mathrm{n}^{\circ} 55\right)$.

Roy, S. (2001). L'analyse de la musique acousmatique : Bilan et propositions. Ph.D. thesis in musicology, dir. J.J. Nattiez. Université de Montréal.

Sheperd, J. (1980). The Musical Coding of Ideologies. In J. Sheperd (Ed.), Whose Music? A Sociology of Musical Languages (pp. 69-124). New Brunswick / London: Transactions Publisher.

Stern, D. (1995). The Motherhood Constellation. London: Karnac Books. Thoresen, L. (assisted by A. Hedman). (2010). Formbuilding patterns and metaphorical meaning. Organised Sound, Vol. 15, n², pp. 82-95. Wishart, T. (1980). Musical Writing, Musical Speaking. In J. Sheperd (Ed.), Whose Music? A Sociology of Musical Languages (pp. 125-154). New Brunswick / London: Transactions Publisher.

— (1996). On Sonic Art - A New and Revised Edition by Simon Emmerson. NewYork / Oxon: Routledge (“Contemporary Music Studies”

\footnotetext{
${ }^{\mathrm{i}}$ All translations are by the author.

ii The concept of proto-narrativization is used here in reference to Imberty's "protonarrative envelope", relative to the perception and distortion of musical time (2005), and distinguish between kinesthesia and proprioception as follows: just as perception is a cognitive operation applied to the exteroceptive (five) senses, proprioception is a cognitive operation applied to the interoceptive sense (kinesthesia). I use those definitions, because the distinction is not always clear, proprioception being sometimes considered as both kinesthesia and statesthesia (is there or not movement in the body?).

${ }^{\text {iii }}$ Muzak Holdings Co. was founded in 1934 and is renowned for the creation and distribution of what is now called "elevator music", applying abusively the findings of the young "music therapy".

iv Let's be honest: the point of those musics is not necessarily the immediately perceptible reality for every listener, but maybe, as it was the case with Boulez and is often the case nowadays, the blurring of temporal directions to benefit the consideration of larger "fields", or just a system to allow formal unity.
} 